\title{
Diversity Analysis of Maize Inbred Lines
}

\section{R. Jaishreepriyanka ${ }^{1}$, Sweta Sinha ${ }^{2}$, ShyamSundar Mandal ${ }^{1 *}$, Birender Singh ${ }^{1}$ and Kumari Rashmi ${ }^{1}$}

${ }^{1}$ Department of Plant Breeding and Genetics, ${ }^{2}$ Department of Molecular Biology and Genetic Engineering, Bihar Agricultural College, Bihar Agricultural University,

Sabour, Bhagalpur 813210, Bihar, India

BAU COMMUNICATION No. 890/200930

*Corresponding author

\section{Keywords}

Morphological diversity, Genetic diversity, SSR markers, Cluster, Mahalanobis distance

\section{Article Info}

Accepted:

20 September 2020

Available Online:

10 October 2020
A B S T R A C T

A set of 10 lines and three testers of maize were grown under optimal and waterlogging conditions, to study the diversity among them. 13 morphological traits were studied and $\mathrm{D}^{2}$ analysis is done. The genotypes were grouped into four clusters by Tocher's method based on Mahalanobis Euclidean distance. Genetic diversity based on SSR markers using 25 markers was also studied. 15 SSR markers with PIC value ranging from 0.13 to 0.32 exhibited polymorphism and the genotypes were grouped into two clusters based on Dice similarity coefficients. The molecular study, did not support the morphological diversity, which can be attributed to the insufficient SSR markers used in the study. However, the trueness of the hybrids can be assessed using the SSR markers. From the diversity study, diverse parents from different cluster can be selected for hybridization programme.

\section{Introduction}

Maize (Zea mays L.) is one of the most important food crops that represents as the staple food of many developed and developing countries. Besides using as food grain, maize is also used as animal feed, fodder and in industries for various purposes, chiefly for starch. It can also be processed and value-added to various processed products.It is greatly preferred by the farmers for its versatility and good yield potential. Therefore maize is considered as a potential crop for crop improvement works. Being predominantly cultivated as a kharif crop in India, maize faces drought and waterlogging stresses during kharif. Waterlogging stress affects the reproductive stage of the crop and 
results in yield loss. However, tolerance to waterlogging is found to be present in the crop and improvement of maize for waterlogging tolerance could be a good scope. Selection of diverse parents is essential for hybridization programme. The objective of the present study is to reveal the diversity in the inbred lines and testers based on morphological traits and simple sequence repeat markers.

\section{Materials and Methods}

The details of the inbred lines and testers used in the investigation are presented in Table 1 and 2 respectively.

\section{Morphological diversity analysis}

The 13 genotypes were evaluated sown in kharif, 2019 in randomized block design with two replications under optimal and waterlogging environments. The waterlogging treatment is given to the waterlogging environment by maintaining stagnant water for seven days, first at knee-high stage and second at tasseling stage. The morphological traits including pre-harvest traits namely, days to 50 per cent tasseling (day), days to 50 per cent silking (day), anthesis - silking interval (day), days to 75 per cent brown husk (day), plant height $(\mathrm{cm})$ and ear height $(\mathrm{cm})$ and post-harvest traits cob length $(\mathrm{cm})$, cob girth (cm), number of rows per cob, number of grains per row, test weight $(\mathrm{g})$, shelling percentage $(\%)$ and grain yield at $15 \%$ moisture $\left(\mathrm{Kg} \mathrm{ha}^{-1}\right)$ were recorded for both environments.

The genetic divergence between genotypes was estimated using Mahalanobis's $\mathrm{D}^{2}$ statistic (1936). The genetic distance between any two populations was computed using the formula

$D^{2} p=d^{1} S^{-1} d$
Where,

$\mathrm{D}^{2} \mathrm{p}=$ Square of distance considering ' $\mathrm{p}$ ' variables

$\mathrm{d}=$ Vector observed differences of the mean values of all the characters (xi $1-x i 2)$

$\mathrm{S}^{-1}=$ inverse of variance and covariance matrix

The lines and testers are clustered into different groups following Tocher's method (Rao, 1952). The intra and inter-cluster distance were calculated as described by Singh and Chaudhary (1977).

\section{Genomic DNA isolation}

Genomic DNA was extracted from fresh leaf tissue of each genotype using modified Dellaporta method of DNA extraction as described by Dellaporta et al., (1983). For this, Two hundred milligrams of leaf samples were cut into small bits with the help of sterile scissors and grinded with $500 \mu \mathrm{l}$ of pre-heated extraction buffer in a pestle and mortar and taken into eppendorf $(1.5 \mathrm{ml})$ tube. The tube is incubated at $65^{\circ} \mathrm{C}$ in water bath for 45 minutes with occasional mixing. Then the tubes were removed from the water bath and $200 \mu \mathrm{l}$ of $5 \mathrm{M}$ potassium acetate was added and mixed by inversion for 15 minutes. It was then kept in $-20{ }^{\circ} \mathrm{C}$ for 10 minutes and then centrifuge at $10,000 \mathrm{rpm}$ for 10 minutes at room temperature. Then the supernatant was transferred to a fresh Eppendorf tube. Equal volume of chilled isopropanol was added to it and mixed gently by inversion and then kept in $-20^{\circ} \mathrm{C}$ deep freezer for 15 minutes. Then it was centrifuged at 10,000 rpm for 10 minutes at room temperature. Supernatant was discarded and DNA pellet was washed twice with $70 \%$ ethanol $(200 \mu \mathrm{l})$ and then final wash with $100 \%$ ethanol. After each washing, tubes were centrifuged at $3000 \mathrm{rpm}$ for 5 minutes at room temperature. Then the alcohol was decanted and DNA pellet was air dried, after which it was dissolved in $100 \mu \mathrm{l}$ 
of $10 \mathrm{mM}$ Tris and Stored at $-20^{\circ} \mathrm{C}$. The quality of DNA was checked by agarose gel electrophoresis. After quantification, the DNA was diluted to a concentration of 40 $\mathrm{ng} / \mu \mathrm{l}$ for SSR analysis.

\section{PCR amplification through SSR primers}

The Diluted DNA samples were subjected to PCR amplification, using the selected SSR primers in automated thermal cycler. $10 \mu \mathrm{L}$ reaction volume contained $2 \mu \mathrm{L}(100 \mathrm{ng})$ DNA, $1 \mu \mathrm{L} 10$ X PCR buffer [MgCl2], $0.2 \mu \mathrm{L}$ $0.2 \mathrm{mMd}$ NTPs, $0.2 \mu \mathrm{L}$ of $0.2 \mu \mathrm{M}$ forward primer, $0.2 \mu \mathrm{L}$ of $0.2 \mu \mathrm{M}$ reverse primer, 0.5 $\mu \mathrm{L}$ TaqDNA Polymerase enzyme $(1 \mathrm{U} / \mu \mathrm{L})$ and $5.9 \mu$ Lautoclaved molecular biology grade water. Reaction condition was programmed as initial hold at $94^{\circ} \mathrm{C}$ for 4 min followed by 25 cycles of denaturation at $94^{\circ} \mathrm{C}$ for $30 \mathrm{~s}$, annealing of primer at $55^{\circ} \mathrm{C}$ for $40 \mathrm{~s}$ and extension at $72^{\circ} \mathrm{C}$ for $40 \mathrm{~s}$. Further extension was allowed at $72^{\circ} \mathrm{C}$ for $5 \mathrm{~min}$. On completion of reaction $2 \mu \mathrm{L}$ gel loading buffer was added.

\section{Scoring and data analysis}

The clear and distinct bands amplified by SSR primers were scored visually for their presence (1) or absence (0) of the corresponding band among the 13 maize genotypes. The polymorphic information content (PIC) values of each primer were calculated using Power Marker 3.5.

The binary data scored was used to construct a dendrogram. Similarity matrix was generated using the SIMQUAL programme of NTSYS-pc software, version 2.02 (Rohlf, 1998). The similarity coefficients were used for cluster analysis and dendrogram was constructed by the Unweighted Pair-Group method (UPGMA) (Sneath and Sokal, 1973).

\section{Results and Discussion}

\section{Morphological diversity}

On the basis of recorded observations, mean and range for the traits were presented in Table 3. The analysis of variance revealed that the genotypes are significantly different for all the traits studied under both environments. The environment was found to be significant for all the traits except days to 50 per cent tasseling and days to 50 per cent silking. From the $\mathrm{D}^{2}$ analysis, the genotypes were grouped into four clusters. The dendrogram obtained on the basis of morphological diversity is presented in fig. 1. Cluster I consists of seven genotypes namely $\mathrm{L}_{5}, \mathrm{~T}_{1}, \mathrm{~L}_{2}, \mathrm{~L}_{7}, \mathrm{~L}_{1}, \mathrm{~L}_{9}$ and $\mathrm{L}_{8}$, cluster II consists of four genotypes namely, $\mathrm{L}_{3}, \mathrm{~L}_{4}, \mathrm{~L}_{6}$ and $\mathrm{L}_{10}$, while cluster III and cluster IV consists of one genotype each, $\mathrm{T}_{2}$ and $\mathrm{T}_{3}$ respectively. The maximum inter-cluster distance was observed between cluster III and cluster IV (90.50), while the minimum inter-cluster distance was observed between cluster I and cluster II (33.94).

\section{Molecular diversity}

The diversity observed based on morphological traits could not be exact, due to environmental interaction. The use of DNA markers can overcome the short back. 15 SSR markers out of 25 showed polymorphism in the 13 genotypes. From the molecular analysis of the 13 genotypes using 15 SSR markers, 43 alleles were observed. The number of alleles per locus ranged from 2 (umc1245, umc2199, bnlg1017, bnlg2046 and bnlg1367) to 4 (bnlg1556, phi109275 and bnlg1401). The gel documentation of 13 genotypes using 15 SSR markers is presented in fig. 3. The details of the 15 SSR markers used in the molecular study is presented in Table 4. 
Table.1 Details of lines

\begin{tabular}{|c|c|c|c|}
\hline S.No. & Code & Pedigree & Source \\
\hline 1 & $\mathrm{~L}_{1}$ & $\begin{array}{l}\text { (CML451-B*4//CML451-BBB/ZEWBc1F2-216-2-2-B-2-B*4-1-B-1-BB///CML451-B*4//CML451- } \\
\text { BBB/CML444-1-BB)/(CML451-B*4//CML451-BBB/LaPostaSeqC7-F86-3-1-2-1-B*6///CML451- } \\
\text { B*4//CML451-BBB/DTPWC9-F24-2-3-1-3-2-1-2-B*4)-B-3-2-BBB1-B }\end{array}$ & $\begin{array}{l}\text { CIMMYT, } \\
\text { Hyderabad }\end{array}$ \\
\hline 2 & $\mathrm{~L}_{2}$ & $\begin{array}{l}\text { ((CML451-B*4//CML451-BBB/LaPostaSeqC7-F18-3-2-2-3-B*7///CML451-B*4//CML451- } \\
\text { BBB/DRB-F2-60-1-1-1-BBB-3-B)-BB/(LPSC7-F96-1-2-1-1-BBB*//OFP39)-6-1-1-1-2BB)-B-11-BB- } \\
\text { B2-B }\end{array}$ & $\begin{array}{l}\text { CIMMYT, } \\
\text { Hyderabad }\end{array}$ \\
\hline 3 & $\mathrm{~L}_{3}$ & (POP501C5\#9/GEMS-0053)-B-9-2-1-1-BB & $\begin{array}{l}\text { CIMMYT, } \\
\text { Hyderabad }\end{array}$ \\
\hline 4 & $\mathrm{~L}_{4}$ & (HSBC1F1-12)DH10-B-\#-BBB & $\begin{array}{l}\text { CIMMYT, } \\
\text { Hyderabad }\end{array}$ \\
\hline 5 & $\mathrm{~L}_{5}$ & $\begin{array}{l}\text { (CLQRCYQ44-B*8/[(CTS013082/P3011F2-5-3-1-3-B*4/Nei402011)-BB/G17C3H883-1-BB-3-3-B)- } \\
\text { BBB-1-B-B }\end{array}$ & $\begin{array}{l}\text { CIMMYT, } \\
\text { Hyderabad }\end{array}$ \\
\hline 6 & $\mathrm{~L}_{6}$ & (POP-501C5\#2/GEMS-0009)-B-15-3-1-1-BBB & $\begin{array}{l}\text { CIMMYT, } \\
\text { Hyderabad }\end{array}$ \\
\hline 7 & $\mathrm{~L}_{7}$ & (AMDROUT1(DT-Tester)C1F1-36-B*5/(CML451/LH82//CML451)-B-8-1-1-1-B)-B-3-B-B1-B & $\begin{array}{l}\text { CIMMYT, } \\
\text { Hyderabad }\end{array}$ \\
\hline 8 & $\mathrm{~L}_{8}$ & $\begin{array}{l}\text { ((CML466/CML165-B//CML466)-BB-9-B*4/(CML465/CML165-B//CML465)-BB-36-B*5)-B-10-B- } \\
\text { B1-B }\end{array}$ & $\begin{array}{l}\text { CIMMYT, } \\
\text { Hyderabad }\end{array}$ \\
\hline 9 & $\mathrm{~L}_{9}$ & (AMDROUT2C2-17-B*4/POP502C5\#4/GEMN-0159)-B-19-3-1-1-B)-B-3-2-B1-B & $\begin{array}{l}\text { CIMMYT, } \\
\text { Hyderabad }\end{array}$ \\
\hline 10 & $\mathrm{~L}_{10}$ & ((CA34505xCA00302)-B-2-1-B-1-B(T)/ZEWBC1F2-216-2-2-B-2-B*4-1-B-1-BB)-B-B1-B-2-BB1-B & $\begin{array}{l}\text { CIMMYT, } \\
\text { Hyderabad }\end{array}$ \\
\hline
\end{tabular}


Table.2 Details of testers

\begin{tabular}{|l|l|l|l|}
\hline S.No & Code & Name & Source \\
\hline $\mathbf{1}$ & $\mathrm{T}_{1}$ & CLO2450 & CIMMYT, Hyderabad \\
\hline $\mathbf{2}$ & $\mathrm{T}_{2}$ & CM501 & IIMR, Ludhiana \\
\hline $\mathbf{3}$ & $\mathrm{T}_{3}$ & BML-7 & ANGRAU, Hyderabad \\
\hline
\end{tabular}

Table.3 Characters with mean and range

\begin{tabular}{|l|l|l|l|}
\hline S.No & Character & Mean & Range \\
\hline $\mathbf{1}$ & Days to 50 per cent tasseling (day) & 62 & $56-67$ \\
\hline $\mathbf{2}$ & Days to 50 per cent silking (day) & 69 & $62-74$ \\
\hline $\mathbf{3}$ & Anthesis - silking interval (day) & 7 & $5-9$ \\
\hline $\mathbf{4}$ & Days to 75 per cent brown husk (day) & 91 & $86-95$ \\
\hline $\mathbf{5}$ & Plant height $(\mathrm{cm})$ & 109.42 & $78.50-151.75$ \\
\hline $\mathbf{6}$ & Ear height $(\mathrm{cm})$ & 43.90 & $27.25-58.00$ \\
\hline $\mathbf{7}$ & Cob length $(\mathrm{cm})$ & 11.70 & $7.30-14.29$ \\
\hline $\mathbf{8}$ & Cob girth $(\mathrm{cm})$ & 3.00 & $2.46-3.60$ \\
\hline $\mathbf{9}$ & No. of rows per cob & 13 & $11-15$ \\
\hline $\mathbf{1 0}$ & No. of grains per row & 23 & $17-29$ \\
\hline $\mathbf{1 1}$ & Test weight $(\mathrm{g})$ & 213.53 & $164.50-280.50$ \\
\hline $\mathbf{1 2}$ & Shelling percentage $(\%)$ & 64.17 & $54.50-74.67$ \\
\hline $\mathbf{1 3}$ & Grain yield at $15 \%$ moisture $(\mathrm{Kg} / \mathrm{ha})$ & 2380.05 & $1940.75-2850.81$ \\
\hline & & & \\
\hline
\end{tabular}


Table.4 Details of SSR markers used in the study

\begin{tabular}{|c|c|c|c|c|c|c|}
\hline S. No. & $\begin{array}{l}\text { Marker } \\
\text { name }\end{array}$ & Forward primer & Reverse primer & Chromosome & $\begin{array}{l}\text { Number } \\
\text { of allele }\end{array}$ & $\begin{array}{l}\text { PIC } \\
\text { value }\end{array}$ \\
\hline 1 & bnlg1064 & CTGGTCCGAGATGATGGC & TCCATTTCTGCATCTGCAAC & 2 & 3 & 0.29 \\
\hline 2 & umc2205 & ATGGTGAGCGAGTGAAAGAGAGAT & CATGATCATTTGGCGATGGTAAT & 2 & 3 & 0.30 \\
\hline 3 & bnlg 1556 & ACCGACCTAAGCTATGGGCT & CCGGTTATAAACACAGCCGT & 1 & 4 & 0.28 \\
\hline 4 & phi109275 & CGGTTCATGCTAGCTCTGC & GTTGTGGCTGTGGTGGTG & 1 & 4 & 0.28 \\
\hline 5 & umc 1245 & TGGTTATGTGCATGATTTTTCCTG & CATGCGTCTGATCTTCAGAATGTT & 1 & 2 & 0.30 \\
\hline 6 & umc1519 & CTCGAGACTCTGGTTCAATCCAAT & CATGCACGTACTTCCCTGATTTTT & 9 & 3 & 0.29 \\
\hline 7 & umc1911 & CCCGGAAGCTGTTTTCTTTTTAAT & CGATCTGGAACGTAAGGATCATCT & 10 & 3 & 0.30 \\
\hline 8 & umc 2199 & ACCGAGTTAAGATTACATCACGCC & TGTTTCCCCTAATAAAGCAAATGAA & 8 & 2 & 0.13 \\
\hline 9 & bnlg 1525 & AGGAATTGCGAGTCTTCCAA & CAACCCCCAAAATGAACAAA & 9 & 3 & 0.27 \\
\hline 10 & umc2038 & ACAGAAACCAATGCATGTGATGAG & TGCATGGTTGCTTCAGCAGT & 4 & 3 & 0.32 \\
\hline 11 & bnlg 1017 & ATTGGAAGGATCTGCGTGAC & CAGCTGGTGGACTGCATCTA & 2 & 2 & 0.31 \\
\hline 12 & bnlg2046 & TTGGTGAAACGGTGAAATGA & CTGGTGAGCTTCACCCTCTC & 8 & 2 & 0.13 \\
\hline 13 & umc1657 & ATGGATGAATATGATCCCACGG & GATCCGCACGTAGCTTTTCG & 9 & 3 & 0.29 \\
\hline 14 & bnlg1401 & CACTCGGTTTTTGCTTAGCC & GTGTCGTCGAGTGCATGC & 9 & 4 & 0.27 \\
\hline 15 & bnlg 1367 & CGACGGCGTACAGAGAGAG & GGTCGCCACCCCACCT & 7 & 2 & 0.13 \\
\hline
\end{tabular}


Table.5 Dice similarity coefficient matrix

\begin{tabular}{|l|l|l|l|l|l|l|l|l|l|l|l|l|l|}
\hline & $\mathbf{L}_{\mathbf{1}}$ & $\mathbf{L}_{\mathbf{2}}$ & $\mathbf{L}_{\mathbf{3}}$ & $\mathbf{L}_{\mathbf{4}}$ & $\mathbf{L}_{\mathbf{5}}$ & $\mathbf{L}_{\mathbf{6}}$ & $\mathbf{L}_{\mathbf{7}}$ & $\mathbf{L}_{\mathbf{8}}$ & $\mathbf{L}_{\mathbf{9}}$ & $\mathbf{L}_{\mathbf{1 0}}$ & $\mathbf{T}_{\mathbf{1}}$ & $\mathbf{T}_{\mathbf{2}}$ & $\mathbf{T}_{\mathbf{3}}$ \\
\hline $\mathbf{L}_{\mathbf{1}}$ & 1.00 & & & & & & & & & & & \\
\hline $\mathbf{L}_{\mathbf{2}}$ & 0.56 & 1.00 & & & & & & & & & & & \\
\hline $\mathbf{L}_{\mathbf{3}}$ & 0.47 & 0.25 & 1.00 & & & & & & & & & \\
\hline $\mathbf{L}_{\mathbf{4}}$ & 0.73 & 0.56 & 0.47 & 1.00 & & & & & & & & & \\
\hline $\mathbf{L}_{\mathbf{5}}$ & 0.69 & 0.59 & 0.38 & 0.63 & 1.00 & & & & & & & \\
\hline $\mathbf{L}_{\mathbf{6}}$ & 0.60 & 0.38 & 0.53 & 0.53 & 0.44 & 1.00 & & & & & & & \\
\hline $\mathbf{L}_{\mathbf{7}}$ & 0.53 & 0.31 & 0.47 & 0.60 & 0.38 & 0.53 & 1.00 & & & & & & \\
\hline $\mathbf{L}_{\mathbf{8}}$ & 0.32 & 0.56 & 0.32 & 0.43 & 0.41 & 0.32 & 0.32 & 1.00 & & & & & \\
\hline $\mathbf{L}_{\mathbf{9}}$ & 0.48 & 0.51 & 0.36 & 0.61 & 0.57 & 0.36 & 0.48 & 0.65 & 1.00 & & & & \\
\hline $\mathbf{L}_{\mathbf{1 0}}$ & 0.69 & 0.59 & 0.57 & 0.57 & 0.59 & 0.51 & 0.57 & 0.48 & 0.47 & 1.00 & & & \\
\hline $\mathbf{T}_{\mathbf{1}}$ & 0.44 & 0.65 & 0.44 & 0.56 & 0.41 & 0.44 & 0.56 & 0.62 & 0.63 & 0.76 & 1.00 & & \\
\hline $\mathbf{T}_{\mathbf{2}}$ & 0.47 & 0.67 & 0.47 & 0.53 & 0.50 & 0.47 & 0.53 & 0.63 & 0.65 & 0.82 & 0.94 & 1.00 & \\
\hline $\mathbf{T}_{\mathbf{3}}$ & 0.45 & 0.67 & 0.39 & 0.58 & 0.42 & 0.45 & 0.52 & 0.63 & 0.59 & 0.72 & 0.97 & 0.91 & 1.00 \\
\hline
\end{tabular}

Fig.1 Dendrogram based on morphological diversity

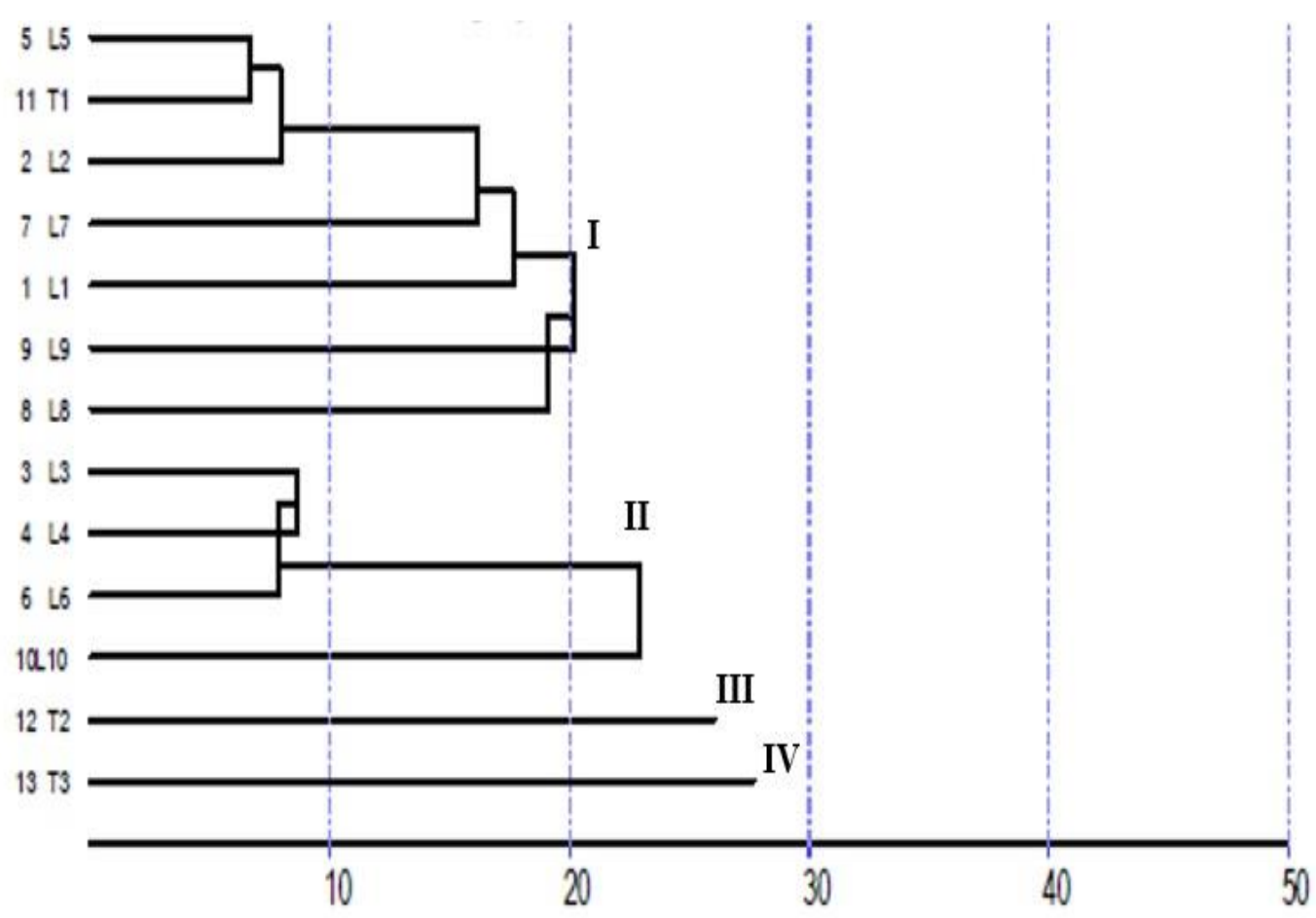

The roman numerals indicate the cluster number 
Fig.2 Dendrogram based on molecular diversity

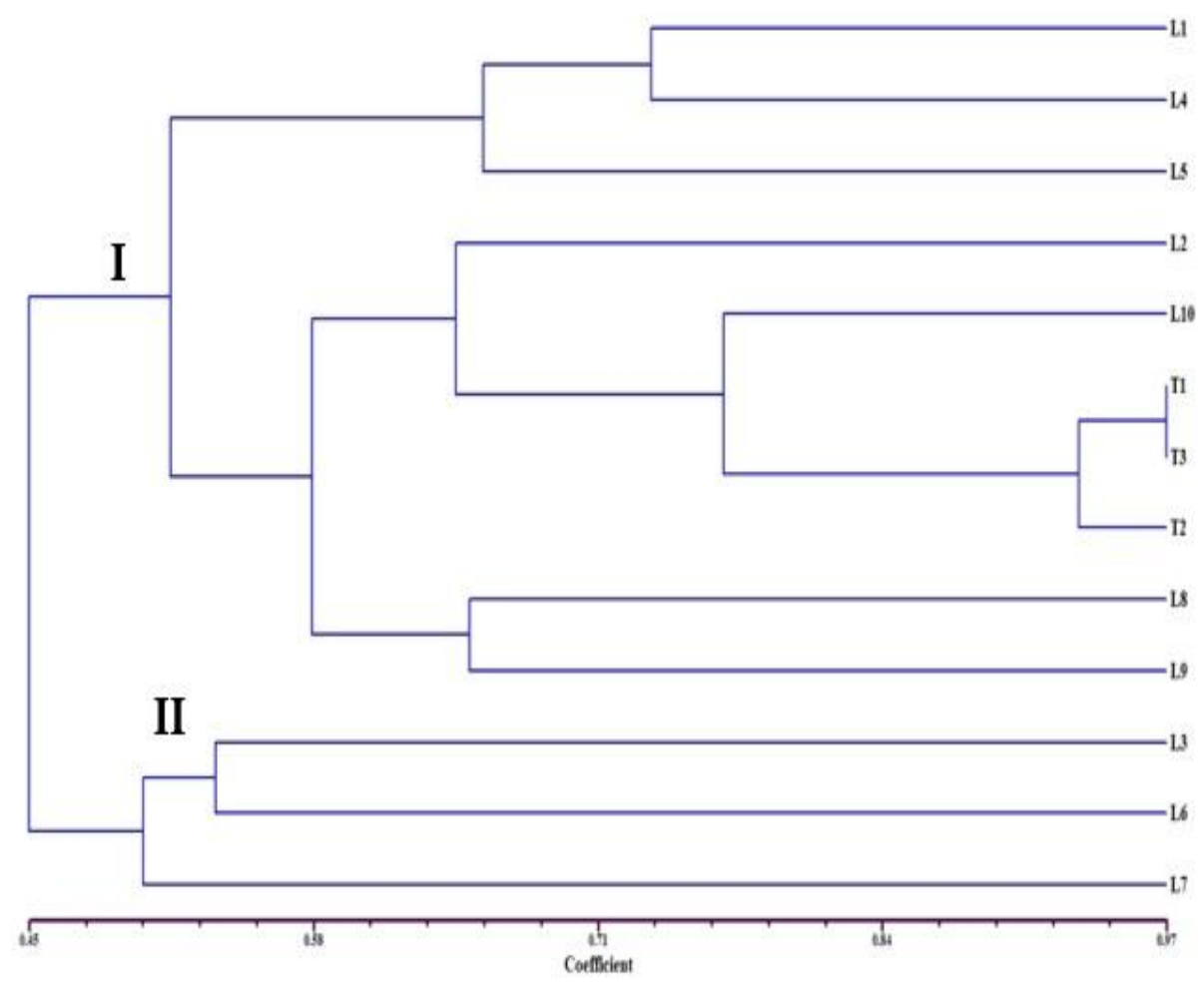

The roman numerals indicate the cluster number.

Fig.3 Ethidium bromide stained 2\% agarose gel revealing polymorphism in 13 genotypes by various SSR markers

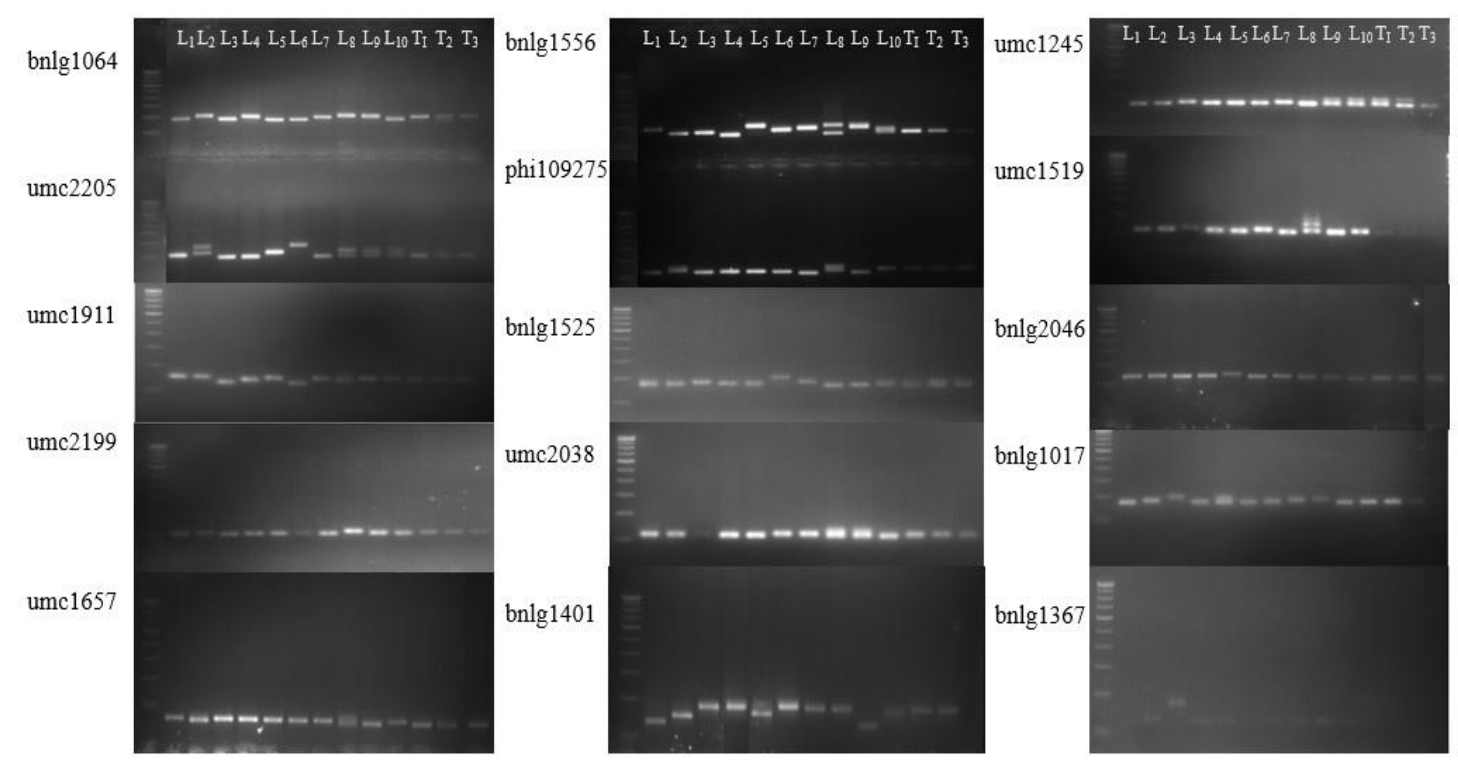


The PIC value for the 15 SSR markers ranges between 0.13 (umc2199, bnlg2046 and bnlg1367) to 0.32 (umc2038). Highest PIC value was an indication that SSR markers are efficient tools for polymorphism analysis (Brown et al., 1996).

\section{Cluster analysis}

Dice similarity coefficient matrix for the 13 genotypes is presented in Table 5. The minimum similarity was observed between $\mathrm{L}_{2}$ and $\mathrm{L}_{3}(0.25)$, while maximum similarity was observed between $\mathrm{T}_{1}$ and $\mathrm{T}_{3}$ (0.97). Based on the Dice similarity coefficient for the 13 genotypes, two clusters were detected. The cluster I was found to have ten genotypes namely, $\mathrm{L}_{1}, \mathrm{~L}_{2}, \mathrm{~L}_{4}$, $\mathrm{L}_{5}, \mathrm{~L}_{8}, \mathrm{~L}_{9}, \mathrm{~L}_{10}, \mathrm{~T}_{1}, \mathrm{~T}_{2}$ and $\mathrm{T}_{3}$ and the cluster II has three genotypes $\mathrm{L}_{3}, \mathrm{~L}_{6}$ and $\mathrm{L}_{7}$. The dendrogram showing clusters based on molecular analysis is presented in fig. 2

It is concluded, from the diversity analysis based on morphological data, four clusters were obtained in the 13 genotypes. The molecular diversity, however contradicts this by revealing two clusters in the 13 genotypes. The results suggest that a better marker system with more number of markers should be considered, due to the genome size and cross pollinated nature of maize. Nevertheless, the SSR markers can be applied in the assessment of the purity of the lines and trueness of the hybrids, which can be developed. The genotypes that are diverse and present in different clusters can be used in hybridization programme.

\section{References}

Brown, S. M., Hopkins, S. E., Mitchell, S. E., Seniour, M.L., Wang, T. Y., Ducan, R. R., Gonzalez-Candelas, F. and Kresovich,
S. 1996. Multiple methods for the identification of polymorphic simple sequence repeats (SSRs) in sorghum (Sorghum bicolor (L.). Theor.Appl. Genet. 93: 190-198.

Dellaporta, S.L., Wood, J. and Hicks, J.B. 1983. A plant DNA minipreparation: Version II. Plant Molecular Biology Reporter. 1: 19 $-21$.

Mahalanobis, P.C.1936. The generalized distance in statistics. Proc. Nat. Acad. Sci. (India). 2:79-85.

Ranatunga, M. A. B., Meenakshisundaram, P., Arumugachamy, S. and Maheswaran, M. 2009. Genetic diversity analysis of maize (Zea mays L.) in breds determined with morphometric traits and simple sequence repeat markers. Maydica. 54: 113-123.

Rao, C.R. 1952. Advanced statistical methods in biometrical research. John Wiley and Sons, Inc. New York. pp. 357-363.

Rohlf, F. J. 1998. On applications of geometric morphometrics to studies of ontogeny and phylogeny. Syst. Biol. 47:147-158.

Shehata, A. I., Al-Ghethar, H. A. and AlHomaidan, A. A.2009. Application of simple sequence repeat (SSR)markers for molecular diversity and heterozygosity analysis in maize inbred lines. Saudi J. of Bio. Sci. 16:57-62.

Singh, P.K., Choudhary, R.D. 1997. Biometrical Methods. In. Quantitative Genetic Analysis, Kalayani Publishers, New Delhi, pp. 178-185.

Sneath, P.H.A. and Sokal, R.R. 1973. Numerical taxonomy. The principles and practice of numerical classification. 573p.

Zaidi, P. H., Yadav, M., Singh, D. K. and Singh, R. P. 2008.Relationship between drought and excess moisture tolerance in tropical maize (Zea mays L.). Aus. J. of Crop Sci. 1 (3): 78-96.

\section{How to cite this article:}

Jaishreepriyanka, R., Sweta Sinha, Shyam Sundar Mandal, Birender Singh and Kumari Rashmi. 2020. Diversity Analysis of Maize Inbred Lines. Int.J.Curr.Microbiol.App.Sci. 9(10): 2765-2773. doi: https://doi.org/10.20546/ijcmas.2020.910.333 